\title{
Silencing of uncoupling protein 2 by small interfering RNA aggravates mitochondrial dysfunction in cardiomyocytes under septic conditions
}

\author{
GUILANG ZHENG, JUANJUAN LYU, SHU LIU, JINDA HUANG, \\ CUI LIU, DAN XIANG, MEIYAN XIE and QIYI ZENG \\ Department of Pediatrics, Zhujiang Hospital, Southern Medical University, Guangzhou, Guangdong 510282, P.R. China
}

Received December 13, 2014; Accepted April 2, 2015

DOI: $10.3892 /$ ijmm.2015.2177

\begin{abstract}
Uncoupling protein 2 (UCP2) regulates the production of mitochondrial reactive oxygen species (ROS) and cellular energy transduction under physiological or pathological conditions. In this study, we aimed to determine whether mitochondrial UCP2 plays a protective role in cardiomyocytes under septic conditions. In order to mimic the septic condition, rat embryonic cardiomyoblast-derived $\mathrm{H} 9 \mathrm{C} 2$ cells were cultured in the presence of lipopolysaccharide (LPS) plus peptidoglycan $\mathrm{G}$ (PepG) and small interfering RNA (siRNA) against UCP2 (siUCP2) was used to suppress UCP2 expression. Reverse transcription quantitative-polymerase chain reaction (RT-qPCR), western blot analysis, transmission electron microscopy (TEM), confocal microscopy and flow cytometry (FCM) were used to detect the mRNA levels, protein levels, mitochondrial morphology and mitochondrial membrane potential (MMP or $\Delta \Psi \mathrm{m}$ ) in qualitative and quantitative analyses, respectively. Indicators of cell damage [lactate dehy-
\end{abstract}

Correspondence to: Professor Qiyi Zeng, Department of Pediatrics, Zhujiang Hospital, Southern Medical University, 253 Gongye Road, Guangzhou, Guangdong 510282, P.R. China

E-mail: 58121444@qq.com

Abbreviations: SIRS, systemic inflammatory response syndrome; SIMD, sepsis-induced myocardial dysfunction; ROS, reactive oxygen species; UCPs, uncoupling proteins; UCP2, uncoupling protein 2; siRNA, small interfering RNA; LPS, lipopolysaccharide; PepG, peptidoglycan G; ncRNA, negative control siRNA; LDH, lactate dehydrogenase; CK, creatine kinase; FCM, flow cytometry; TEM, transmission electron microscopy; MMP or $\Delta \Psi \mathrm{m}$, mitochondrial membrane potential; DCFH-DA, 2',7'-dichlorofluorescein diacetate; DCFH, 2',7'-dichlorofluorescein; mtDNA, mitochondrial DNA; nDNA, nuclearDNA;ETC,electron transportchain;JC-1,5,5',6,6'-tetrachloro1,1',3,3'-tetraethylbenzimidazole-carbocyanide iodine

Key words: uncoupling protein 2, mitochondrial DNA, mitochondrial function, small interfering RNA, sepsis, $\mathrm{H} 9 \mathrm{C} 2$, reactive oxygen species, mitochondrial membrane potential drogenase (LDH), creatine kinase (CK), interleukin (IL)-6 and tumor necrosis factor (TNF)- $\alpha$ in the culture supernatant] and mitochondrial function [ROS, adenosine triphosphate (ATP) and mitochondrial DNA (mtDNA)] were detected. Sepsis enhanced the mRNA and protein expression of UCP2 in the $\mathrm{H} 9 \mathrm{C} 2$ cells, damaged the mitochondrial ultrastructure, increased the forward scatter (FSC)/side scatter (SSC) ratio, increased the CK, LDH, TNF- $\alpha$ and IL- 6 levels, and lead to the dissipation of MMP, as well as the overproduction of ROS; in addition, the induction of sepsis led to a decrease in ATP levels and the deletion of mtDNA. The silencing of UCP2 aggravated H9C2 cell damage and mitochondrial dysfunction. In conclusion, our data demonstrate that mitochondrial morphology and funtion are damaged in cardiomyocytes under septic conditions, while the silencing of UCP2 using siRNA aggravated this process, indicating that $\mathrm{UCP} 2$ may play a protective role in cardiomyocytes under septic conditions.

\section{Introduction}

Sepsis is a systemic inflammatory response syndrome (SIRS) caused by probable or documented infection, which continues to pose serious clinical challenges. Sepsis affects individuals of all ages and is the leading cause of morbidity and mortality for critically ill patients (1). Sepsis-induced myocardial dysfunction (SIMD), one of the main predictors of morbidity and mortality associated with sepsis, is present in $>40 \%$ of cases of sepsis (2). SIMD increases the mortality rate of sepsis by up to $70 \%$ (3). A number of studies on both patients and experimental animals (4-6) have indicated that mitochondrial dysfunction seems to be related to the severity and prognosis of sepsis. The heart is rich in mitochondria, and thus the role of mitochondrial damage in SIMD has received much attention. Previous studies have indicated that multiple aspects of mitochondrial dysfunction contribute to SIMD, such as the overproduction of reactive oxygen species (ROS), the altered generation of adenosine triphosphate (ATP) and the disruption of mitochondrial membrane potential (MMP or $\Delta \Psi \mathrm{m})(7,8)$.

Uncoupling proteins (UCPs) may constitute a vital link between ATP and ROS production $(9,10)$; they are inner mitochondrial membrane proteins that disperse the mitochondrial proton gradient by translocating $\mathrm{H}^{+}$across the inner membrane. 
Of the 5 UCP homologues, uncoupling protein 2 (UCP2) is ubiquitously expressed; for example, it is expressed in the liver, brain, pancreas, adipose tissue, immune cells, spleen, kidneys and heart. In vitro and in vivo, by modulating MMP, as well as the ATP and ROS levels, the upregulation of UCP2 plays a neuroprotective role (11-13), while UCP2 knockout mice present with increased mitochondrial ROS production (9). In addition, UCP2 is involved in the regulation of other physiological or pathological events, such as in the formation of atherosclerotic plaque, food intake and metabolic diseases (14). Given its central role in regulating mitochondrial ROS production and cellular energy transduction, we hypothesized that UCP2 may play a protective role in sepsis. To the best of our knowledge, the possible role of UCP2 in sepsis has received little attention. However, some scholars have found that UCP2 deficiency provides protection in acute liver failure induced by endotoxemic stress (15) and in the pathogenesis of experimental leishmaniosis (16). Nonetheless, whether UCP2 plays a protective role in sepsis needs to be determined.

In early experiments, we found high levels of UCP2 gene and protein expression in septic myocardial tissue (unpublished data), which is consistent with the findings of other studies $(17,18)$. However, the exact role of UCP2 in myocardial cells under septic conditions remains to be determined. It remains unclear as to whether UCP2 plays a protective role in myocardial cells under septic conditions by regulating MMP and the generation of mitochondrial ROS. We hypothesized that UCP2 may regulate MMP and mitochondrial function under septic conditions. In this study, we measured the levels of ROS and ATP production, as well as the extent of MMP and other relative indicators following the silencing of UCP2 by RNA interference technology in $\mathrm{H} 9 \mathrm{C} 2$ cardiomyocytes under septic conditions.

\section{Materials and methods}

Small interfering RNA (siRNA) transfection. Two siRNAs against UCP2 (siUCP2) and negative control siRNA (ncRNA) were synthesized by Shanghai GenePharma Co., Ltd. (Shanghai, China). The sequences of siRNA1 were as follows: forward, 5'-GCA CUG UCG AAG CCU ACA A dTdT-3' and reverse, 5'-UUG UAG GCU UCG ACA GUG C dTdT-3'. The sequences of siRNA2 were forward, 5'-CCU CAU GAC AGA CGA CCU C dTdT-3' and reverse, 5'-GAG GUC GUC UGU CAU GAG G dTdT-3'. The sequences of ncRNA were forward, 5'-UUC UCC GAA CGU GUC ACG UTT-3' and reverse, 5'-ACG UGA CAC GUU CGG AGA ATT-3'. The siRNAs were transfected using Lipofectamine 2000 (Invitrogen Life Technologies, Carlsbad, CA, USA) according to the manufacturer's instructions. Briefly, siRNA (final concentration $80 \mathrm{nmol} / \mathrm{l}$ ) and Lipofectamine 2000 were firstly diluted separately in Opti-DMEM medium $\left(\right.$ Gibco $^{\mathrm{TM}}$; Life Technologies, Grand Island, NY, USA) without antibiotics or serum, and incubated together for $20 \mathrm{~min}$. The complexes were then added to the H9C 2 cells. After $6 \mathrm{~h}$ of incubation, the medium was changed as needed. The silencing efficiency of the 2 siRNAs was tested in experiments of transient RNA interference; the UCP2 transcript was assayed by reverse transcription-quantitative PCR (RT-qPCR) $48 \mathrm{~h}$ after infection. siRNA2, which showed the most prominent silencing effect (69\% knockdown efficiency of mRNA) was used for the subsequent experiments. For further experiments, the H9C2 cells were cultured following transfection.

Cell culture and treatment. Rat embryonic cardiomyoblast-derived H9C2 cells were purchased from the Typical Culture Preservation Commission Cell Bank, Chinese Academy of Sciences (Shanghai, China). H9C2 cells mimic most of the characteristics of adult cardiomyocytes and this is an ideal cell line with which to explore the role of UCP2 in the septic myocardium in a cell culture system. The cells were cultured in DMEM (Gibco-BRL, Beijing, China) supplemented with $10 \%$ fetal calf serum and $5 \% \mathrm{CO}_{2}$ at $37^{\circ} \mathrm{C}$. The $\mathrm{H} 9 \mathrm{C} 2$ cells were passaged regularly and subcultured to $75 \%$ confluence prior to use in the experiments. In order to simulate sepsis, some cells were cultured in the presence of $2 \mu \mathrm{g} / \mathrm{ml}$ lipopolysaccharide (LPS, from Escherichia coli O111:B4; Sigma-Aldrich, St. Louis, MO, USA) plus $20 \mu \mathrm{g} / \mathrm{ml}$ peptidoglycan G (PepG, from Micrococcus luteus; Sigma-Aldrich). The experimental design consisted the following 4 groups: i) the control group, cells were treated with saline only; ii) the LPS/PepG group, cells treated with LPS and PepG as described above; iii) the LPS/PepG + siRNA group, cells transfected with siRNA2 and $24 \mathrm{~h}$ later treated with LPS plus PepG as described above; and iv) the LPS/PepG + ncRNA group, cells transfected with ncRNA and $24 \mathrm{~h}$ later treated with LPS plus PepG as described above. Further experiments were carried out $24 \mathrm{~h}$ following stimulation with LPS plus PepG.

$R T$ - $q P C R$. To examine the mRNA levels of UCP2, total RNA was extracted from the H9C2 cells using TRIzol reagent (Invitrogen Life Technologies) and then reverse transcribed and synthesized into cDNA using RT-PCR kits (Toyobo Co., Ltd., Osaka, Japan). RT-PCR amplification reaction was performed in a volume of $10 \mu \mathrm{l}$ containing $0.25 \mu \mathrm{l}$ forward/reverse primers, $5 \mu \mathrm{l}$ SYBP-Green PCR Master Mix and $4 \mu \mathrm{l}$ cDNA. PCR was performed for 45 cycles of $5 \mathrm{~min}$ at $95^{\circ} \mathrm{C}, 15 \mathrm{sec}$ at $95^{\circ} \mathrm{C}$, and $30 \mathrm{sec}$ at $60^{\circ} \mathrm{C}$. The threshold cycle $(\mathrm{Ct})$ was obtained from triplicate samples and averaged. Calculations were based on the ' $\Delta \Delta \mathrm{Ct}$ method' using the equation $\mathrm{R}$ (ratio) $=2^{-\Delta \Delta \mathrm{Ct}}$ and standardized by the housekeeping gene, 18s RNA. The specific primers for UCP2 (Shanghai GenePharma Co., Ltd.) were: forward, 5'-GGG CAC CTG TGG TGC TAC CTG-3' and reverse, 5'-ATG AGC TTT GCC TCC GTC CGC-3'; and those for 18s RNA were: forward, 5'-CCA TCC AAT CGG TAG TAG C-3' and reverse, 5'-GTA ATG GCG GGT CAT AAG-3'.

Western blot analysis. The H9C2 cells were lysed in 2X SDS sample buffer and the protein concentrations in the supernatants were measured by BCA Protein assay. An equal amount of protein $(30 \mathrm{mg}$ ) from each sample was subjected to $12-15 \%$ SDS-PAGE gels and then transferred onto PVDF filter membranes (Millipore, Billerica, MA, USA). The membranes were blocked with $5 \%(\mathrm{w} / \mathrm{v})$ non-fat dried skimmed milk powder in wash buffer (Tris-buffered saline/1\% Tween-20) for $1 \mathrm{~h}$ and subsequently incubated with primary antibodies overnight at a dilution recommended by the suppliers. The membranes were washed 3 times with wash buffer and then incubated with corresponding horseradish peroxidase-conjugated secondary antibodies. The protein signal was developed 
using ECL substrate (Beyotime Institute of Biotechnology, Jiangsu, China) according to the manufacturer's instructions. The immunoreactive protein bands were visualized using the In-Vivo Imaging System F (Eastman Kodak Co., Rochester, NY, USA). The band intensity was quantified using of Gel-Pro Analyzer 4.0 software.

Measurement of lactate dehydrogenase ( $L D H)$ and creatine kinase (CK) levels. Forty-eight hours after cell treatment, the culture supernatant was collected for the subsequent measurement of $\mathrm{CK}$ and $\mathrm{LDH}$ levels. The release of the cytosolic enzymes, $\mathrm{CK}$ and $\mathrm{LDH}$, indicators of cytotoxicity, reflected a loss of membrane integrity in the damaged cells and was detected by colorimetric assay. CK and LDH activity was measured using commercially available kits (Nanjing Jiancheng Bioengineering Institute, Jiangsu, China), according to the manufacturer's instructions. Absorbance was respectively read at 660 and $440 \mathrm{~nm}$ on a multifunctional microplate reader (SpectraMax M5/M5e; Molecular Devices, Sunnyvale, CA, USA). The release of CK and $\mathrm{LDH}$ was calculated relative to the percentage of the control group.

Enzyme-linked immunosorbent assay (ELISA) for the detection of interleukin (IL)- 6 and tumor necrosis factor (TNF)- $\alpha$. Forty-eight hours after cell treatment, the culture supernatant was collected for the subsequent measurement of IL-6 and TNF- $\alpha$ expression levels. The culture supernatants were measured using commercially available ELISA kits (Cusabio Life Science, Wuhan, China). All procedures were performed strictly as per the instructions of the manufacturer. The samples were analyzed in triplicate.

Degree of mitochondrial swelling. To determine the large amplitude swelling of the H9C2 cells, the isolation of the mitochondria and the cytosol was performed using the Cell Mitochondria Isolation kit (Beyotime Institute of Biotechnology). Mitochondrial fractions were separated by differential centrifugation according to the manufacturer's instructions. Briefly, the H9C2 cells were incubated in ice-cold mitochondrial lyses buffer for $15 \mathrm{~min}$. The cell suspension was then poured into a glass homogenizer and homogenized for 20 strokes. The homogenate was subjected to centrifugation at $600 \mathrm{x} \mathrm{g}$ for $10 \mathrm{~min}$ at $4^{\circ} \mathrm{C}$ to remove the nuclei and unbroken cells. The supernatant was then collected and centrifuged again at $11,000 \mathrm{x}$ g for $15 \mathrm{~min}$ at $4^{\circ} \mathrm{C}$ to obtain the mitochondrial fraction. Samples of mitochondria were dissolved in lysis buffer and subjected to flow cytometry (FCM). The size [(forward scatter (FSC)] and structure [side scatter (SSC)] of the mitochondria was determined. The degree of mitochondrial swelling was quantified as the FSC/SSC ratio, as previously described (19).

Transmission electron microscopy (TEM). The H9C2 cells were collected and fixed in a solution containing $3.0 \%$ formaldehyde, $1.5 \%$ glutaraldehyde in $100 \mathrm{mM}$ cacodylate containing 2.5\% sucrose ( $\mathrm{pH} 7.4)$. The $\mathrm{H} 9 \mathrm{C} 2$ cells were stained with $4 \%$ aqueous uranyl acetate, dehydrated, infiltrated and embedded in epoxyresin. Ultrathin sections $(80 \mathrm{~nm})$ were cut and imaged using a Hitachi transmission electron microscope (H-7500; Hitachi, Tokyo, Japan).
MMP (or $\Delta \Psi m) . \Delta \Psi \mathrm{m}$ was assessed using a laser scanning confocal microscope (LSCM, FV10i-W; Olympus Corp., Tokyo, Japan) and a flow cytometer (BD FACSAria; BD Biosciences, Franklin Lakes, NJ, USA) with 5,5',6,6'-tetrachloro-1,1',3,3'tetraethylbenzimidazole-carbocyanide iodine (JC-1; Beyotime Institute of Biotechnology) staining. The H9C2 cells were stained with JC-1 for $20 \mathrm{~min}$ at $37^{\circ} \mathrm{C}$ after $24 \mathrm{~h}$ of incubation with LPS/PepG. Cells on a 35-mm confocal special dish were scanned using an LSCM, and mitochondrial suspension was detected by FCM. Fluorescence was read at $488 \mathrm{~nm}$ excitation and $530 \mathrm{~nm}$ emission for green, and at $540 \mathrm{~nm}$ excitation and $590 \mathrm{~nm}$ emission for red. Cells treated with $10 \mu \mathrm{M}$ carbonyl cyanide m-chlorophenylhydrazone (CCCP) which can cause the dissipation of $\Delta \Psi \mathrm{m}$ were used as positive controls. The ratio of aggregated $\mathrm{JC}-1$ (red fluorescence) and monomeric JC-1 (green fluorescence) represented the $\Delta \Psi \mathrm{m}$ of $\mathrm{H} 9 \mathrm{C} 2$ the cells.

Assay of intracellular ROS. The production of ROS in the H9C 2 cells was fluorometrically monitored using the non-fluorescent probe, 2',7'-dichlorofluorescein diacetate (DCFH-DA) (Beyotime Institute of Biotechnology). DCFH-DA passively diffuses into cells and is deacetylated, changing into the fluorescent compound, 2',7'-dichlorofluorescein (DCFH). DCFH reacts with ROS to form the fluorescent product, DCF, which is trapped inside the cells. Cells in 6-well culture dishes were trypsinized, and collected by centrifugation. DCFH-DA, diluted to a final concentration of $10 \mu \mathrm{M}$ with DMEM, was added to the $\mathrm{H} 9 \mathrm{C} 2$ cells followed by incubation at $37^{\circ} \mathrm{C}$ for 20 min. Following treatment with DCFH-DA, the H9C2 cells were washed 3 times with PBS. DCF fluorescence was then read using a multifunctional microplate reader (SpectraMax M5/M5e; Molecular Devices) at an excitation wavelength of $488 \mathrm{~nm}$ and an emission wavelength of $525 \mathrm{~nm}$. The increase in the value of the levels of ROS was expressed as a percentage of the control. To visually observe the changes in ROS production, fluorescence images were acquired using a fluorescence microscope with 450-490 nm (excitation) and $520 \mathrm{~nm}$ (emission) filters.

Detection of cellular ATP levels. The cellular amount of ATP was measured using a firefly luciferase-based ATP assay kit (Beyotime Institute of Biotechnology) according to the manufacturer's instructions. Briefly, after $48 \mathrm{~h}$ of treatment, the $\mathrm{H} 9 \mathrm{C} 2$ cells were treated with lysis buffer and centrifuged at $12,000 \times \mathrm{g}$ for $8 \mathrm{~min}$. In 24-well plates, $50 \mu \mathrm{l}$ of each supernatant were mixed with $100 \mu$ ATP detection working dilution. Luminance [in relative luminance units (RLU)] was measured using a multifunctional microplate reader (SpectraMax M5/M5e; Molecular Devices). A standard curve of the ATP concentration was prepared from a known amount (0.01-10 $\mu \mathrm{M})$ and the protein concentration in each group was detected using the Bradford protein assay (Beyotime Institute of Biotechnology, Jiangsu, China). The ATP levels were expressed as $\mathrm{nmol} / \mathrm{mg}$ protein.

Determination of mitochondrial DNA (mtDNA) copy number by real-time PCR. Total genomic DNA was extracted using a DNA extraction kit (Qiagen, Hilden, Germany), and the DNA concentration was measured by optical density. The mtDNA 

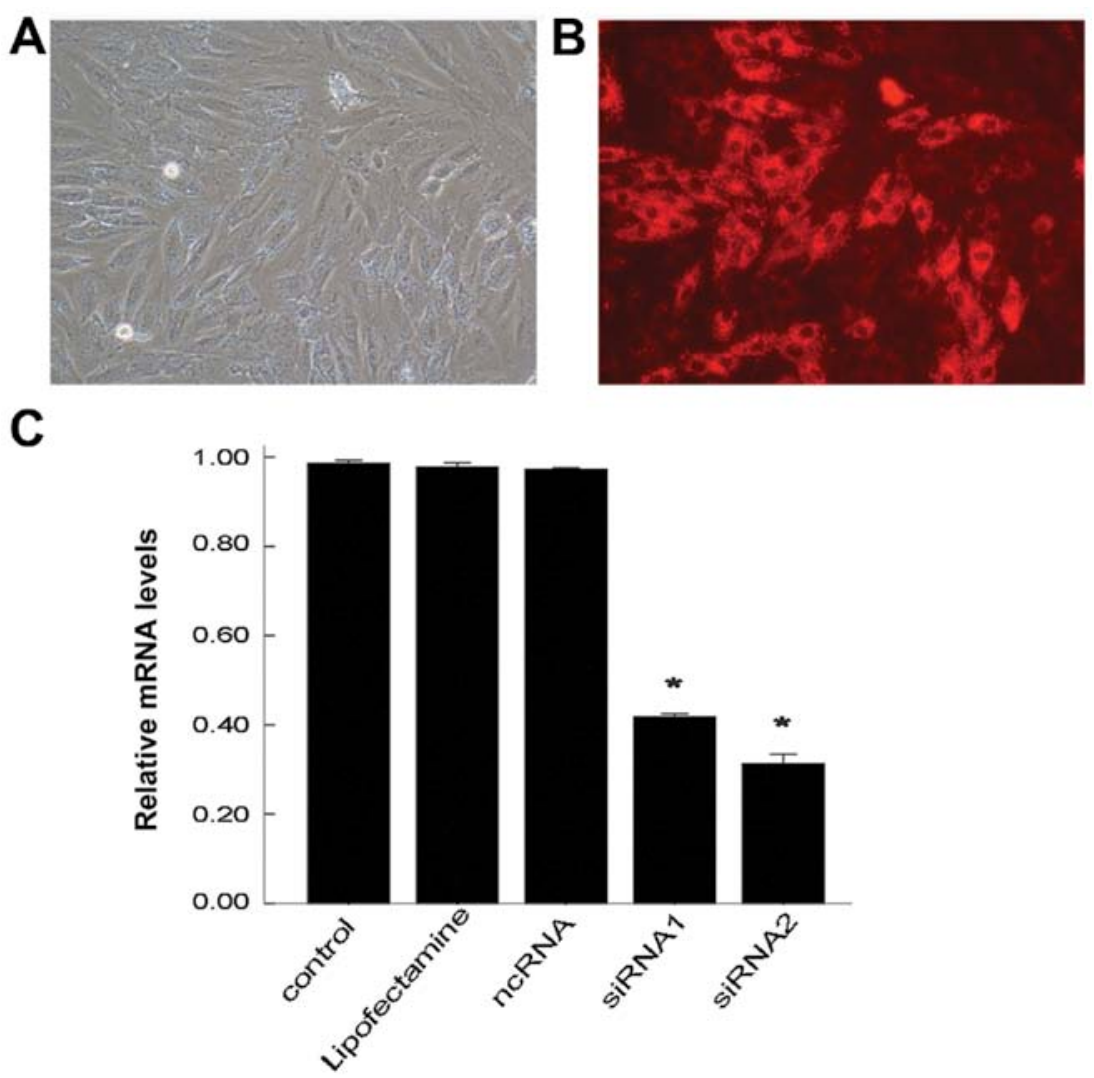

Figure 1. The transfection and knockdown efficiency of siRNA against UCP2 in H9C2 cells. (A and B) H9C2 cells transfected with control siRNA (Cy3) emitted red fluorescence. The transfection efficiency is expressed as the ratio of the number of red fluorescence cells over all cells by fluorescence microscopy (magnification, x20). (C) The knockdown efficiency of siRNA against UCP2 in H9C2 cells. H9C2 cells were left untransfected (control), transfected with Lipofectamine 2000 (no siRNA), transfected with negative control siRNA (ncRNA), or transfected with siRNA1 or 2 . After $24 \mathrm{~h}$, the mRNA levels of uncoupling protein 2 (UCP2) were determined by RT-qPCR with normalization to 18 s RNA. "P<0.05 vs. control.

copy number was obtained according to the manufacturer's instructions (AceQ ${ }^{\mathrm{TM}}$ qPCR SYBR ${ }^{\circledR}$-Green Master Mix; Promega Biotech Co., Ltd, Beijing, China). Briefly, DNA primers were designed to detect Cytb and 18s RNA at a maximum amplicon length of $150 \mathrm{bp}$ : 18s RNA forward, 5'-GTAAGTGCGGGTCATAAG-3' and reverse, 5'-CCATCCAATCGGTAGTAGC-3'; Cytb forward, 5'-GTCGAATGAATTTGAGGGGG-3' and reverse, 5'-GAGGAGGTGAACGATTGCTAGG-3'. The PCR reaction mixture contained 2X SYBR-Green PCR Master Mix $10 \mu \mathrm{l}$, each primer $0.5 \mu \mathrm{l}$, and total genomic DNA $4.0 \mu \mathrm{l}$, and $\mathrm{dH}_{2} \mathrm{O}$ $5.0 \mu \mathrm{l}$. The real-time PCR conditions were $5 \mathrm{~min}$ at $95^{\circ} \mathrm{C}$ and followed by 40 cycles of $15 \mathrm{sec}$ at $95^{\circ} \mathrm{C}$ and $34 \mathrm{sec}$ at $60^{\circ} \mathrm{C}$. The $\mathrm{Ct}$ is the cycle at which the first significant increase in the fluorescence signal is detected. Relative values for $\mathrm{Cytb}$ and 18s RNA in the samples were used to obtain the ratio of mtDNA to nuclear DNA (nDNA) in that sample.

Statistical analysis. The experimental values were obtained from 3 independent experiments with a similar pattern and are expressed as the means \pm SD. For the determination of the statistical differences between the control and treatment groups, we used ANOVA, followed by post hoc pairwise comparison (LSD) tests for analysis. Statistical analysis was carried out using the SPSS software package 20.0. Statistical significance was set at $\mathrm{P}<0.05$.

\section{Results}

Successful transfection of siRNA and knockdown efficiency of siUCP2. The H9C2 cells were successfully transfected with siRNA-cy3 using Lipofectamine 2000 and observed under a fluorescence microscope. The H9C2 cells transfected with siRNA-cy3 all emitted red fluorescence. The transfection efficiency after $24 \mathrm{~h}$ was determined through the observation of red fluorescence (Fig. 1A and B). The transfection efficiency was $85 \%$ which was evaluated in $500 \mathrm{H} 9 \mathrm{C} 2$ cells randomly.

To examine the function of UCP2 in sepsis, 2 siRNAs against UCP2 were used to specifically suppress UCP2 mRNA expression in this study. The H9C2 cells were either left untransfected (control), transfected with Lipofectamine 2000 (no siRNA), transfected with ncRNA, or with siRNA1 or 2. After $24 \mathrm{~h}$, the mRNA levels of UCP 2 were determined by RT-qPCR. The mRNA level of UCP2 was reduced by up to nearly $69 \%$ following transfection with siRNA2 and by $59 \%$ following transfection with siRNA1 compared with the controls (Fig. 1C). There were no significant changes observed in the UCP2 mRNA level in the cells transfected with Lipofectamine only or with ncRNA compared with the control group. siRNA2 was thus selected for use in further experiments.

Effects of siRNA on the levels of CK, LDH, IL- 6 and TNF- $\alpha$. The CK and LDH levels are biochemical markers for the 
A
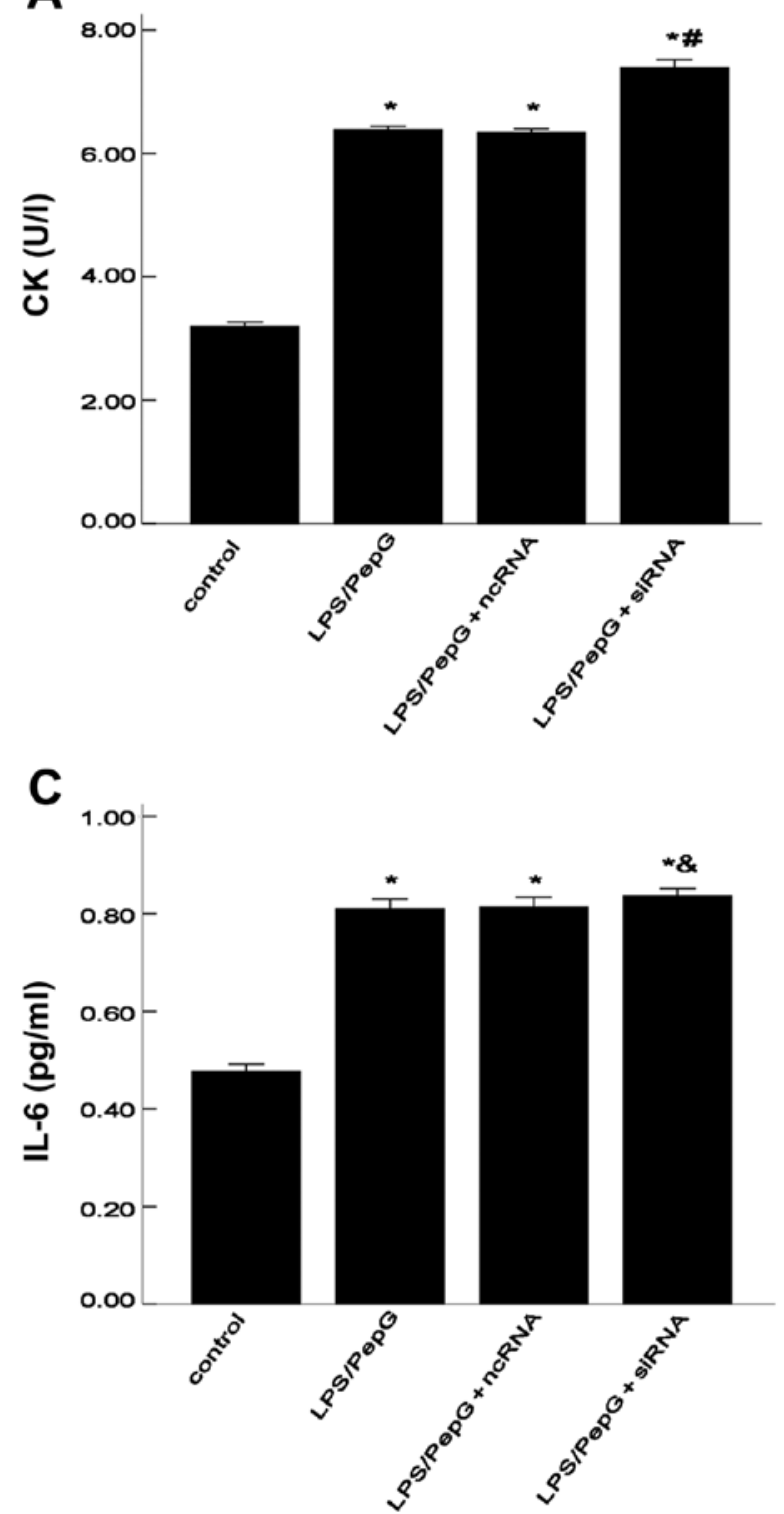

B

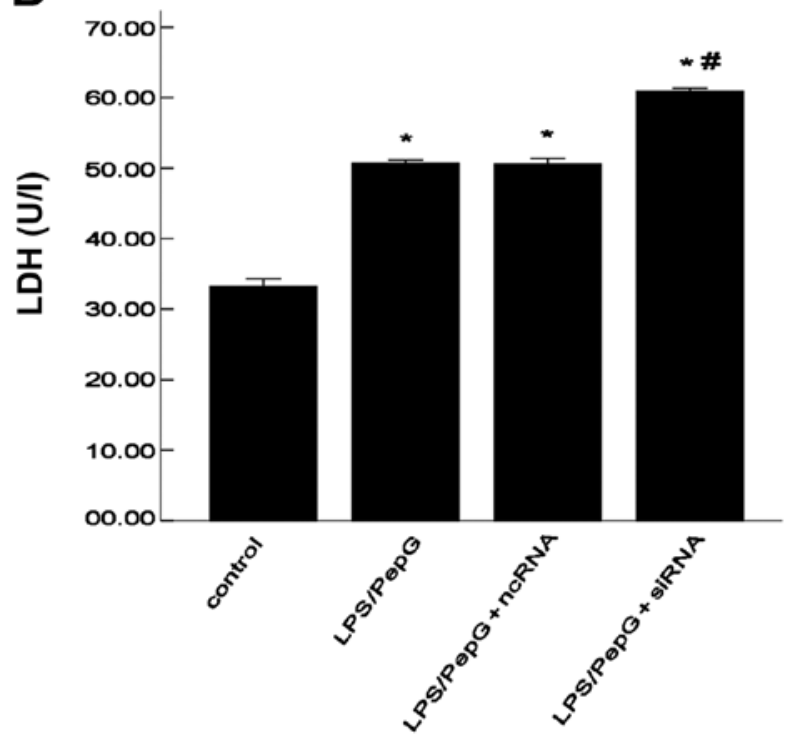

D

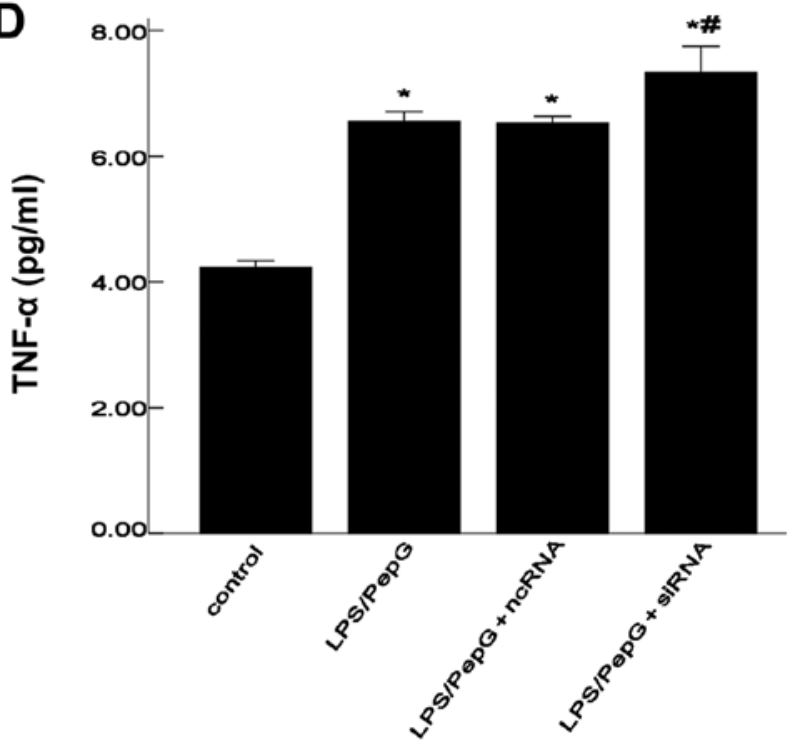

Figure 2. Effects of siRNA on the levels of (A) creatine kinase (CK), (B) lactate dehydrogenase (LDH), (C) interleukin (IL)-6 and (D) tumor necrosis factor (TNF)- $\alpha$ in the culture supernatant of lipopolysaccharide (LPS)/peptidoglycan G (PepG)-treated H9C2 cells. Control, LPS/PepG, LPS/PepG + negative control siRNA (ncRNA), LPS/PepG + siRNA represent the control, LPS/PepG, LPS/PepG + ncRNA and LPS/PepG + siRNA group, respectively. The data are expressed as the means $\pm \mathrm{SD} ; \mathrm{n}=3$ for each group. ${ }^{*} \mathrm{P}<0.05$ vs. control. ${ }^{\#} \mathrm{P}<0.05,{ }^{\&} \mathrm{P}>0.05$ vs. $\mathrm{LPS} / \mathrm{PepG}$ group.

extent of injury to H9C2 cells (20-22). The increased levels of $\mathrm{CK}$ and $\mathrm{LDH}$ in the culture supernatant indicate the degree of cell injury. TNF- $\alpha$ and IL-6 are important pro-inflammatory cytokines in sepsis. As shown in Fig. 2, following treatment with LPS/PepG, the levels of CK, LDH, TNF- $\alpha$ and IL-6 in the cell supernatant notably increased compared with those in the control group (no treatment; all $\mathrm{P}<0.05$ ). In other words, compared with the control group, treatment with LPS/PepG induced a 2-fold increase in CK levels, a 1.5-fold increase in LDH levels, a 1.6-fold increase in IL-6 levels and a 1.5-fold increase in TNF- $\alpha$ levels. The significant increase in CK, LDH, TNF- $\alpha$ and IL- 6 levels in the culture supernatant indicated that the H9C2 cell model of sepsis had been successfully constructed. Subsequently, we further explored the effects of siRNA on H9C2 cells under septic conditions. Supernatants from the cells treated with LPS/PepG + siRNA had markedly higher $\mathrm{CK}, \mathrm{LDH}$ and $\mathrm{TNF}-\alpha$ concentrations (all $\mathrm{P}<0.05$; Fig. 2A, B and D) compared with the cells treated with LPS/PepG; however, no statistically significant differences were observed in the IL- 6 concentration ( $P>0.05$; Fig. 2C) when compared with the cells treated with LPS/PepG. Compared with the LPS/PepG group, ncRNA had no effect on the CK, LDH, TNF- $\alpha$ and IL- 6 levels in the culture supernatant (all $\mathrm{P}>0.05$; Fig. 2).

UCP2 mRNA and protein levels in H9C2 cells under septic conditions. To determine whether sepsis increases the UCP2 mRNA and protein levels, the H9C2 cells were treated with LPS plus PepG or saline. After 48 h, total RNA was extracted for RT-qPCR and total protein was extracted for western blot 


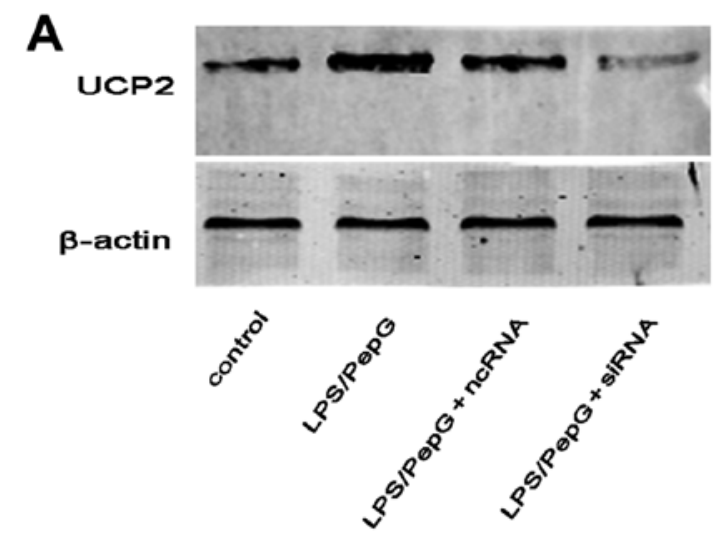

B

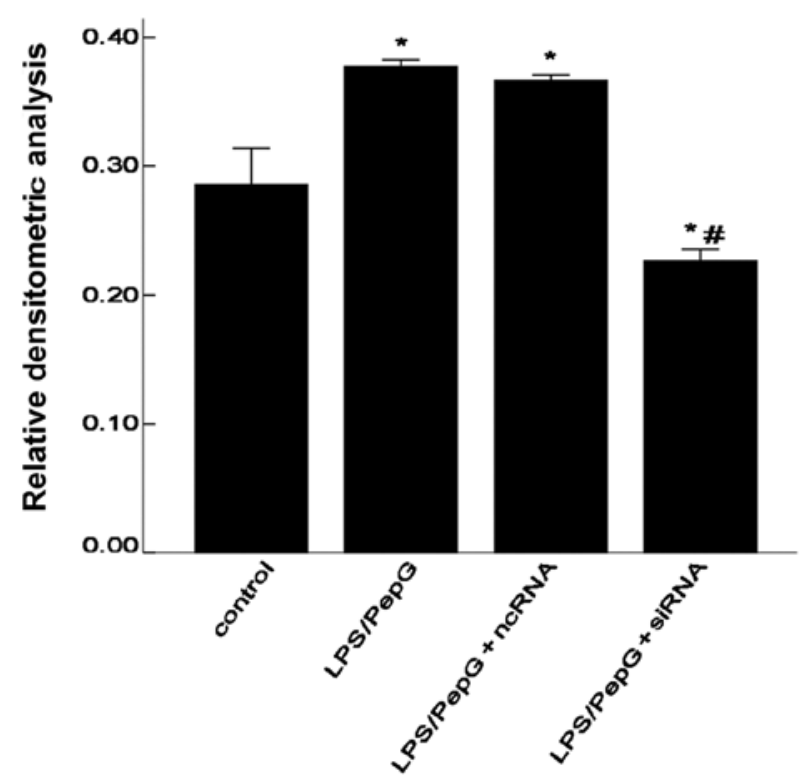

C

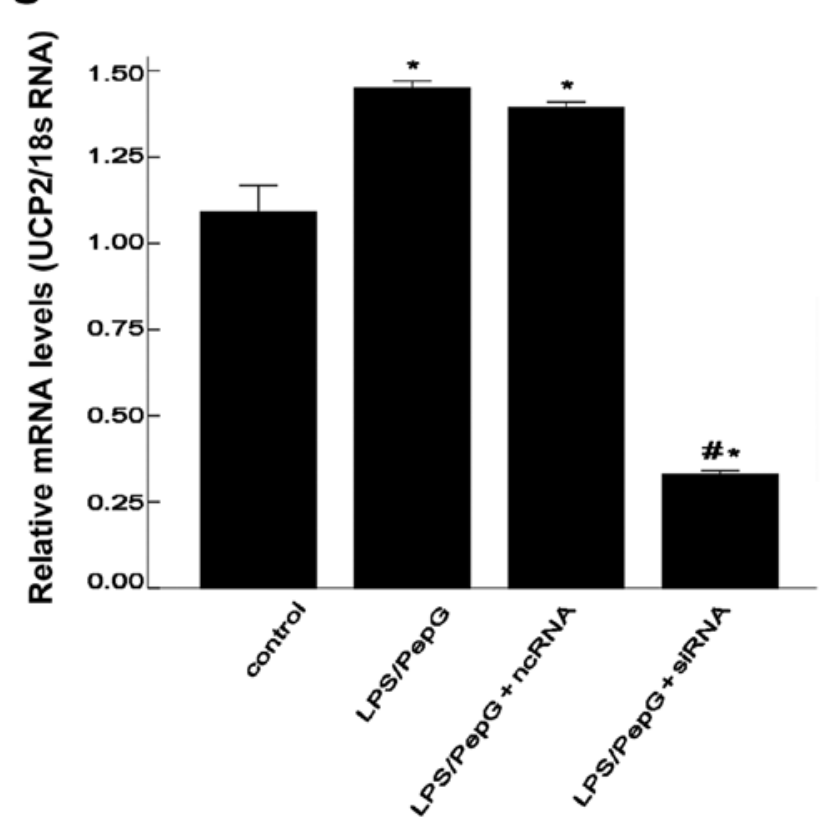

Figure 3. Uncoupling protein 2 (UCP2) mRNA and protein levels in H9C2 cells. Total RNA was extracted and the relative (A and B) protein and (C) mRNA levels of UCP2 were determined by western blot analysis ( $\beta$-actin was used as a loading control) and RT-qPCR (with normalization to 18s RNA), respectively. Values are the means $\pm \mathrm{SD} ; \mathrm{n}=3$ for each group. ${ }^{*} \mathrm{P}<0.05$ vs. control. ${ }^{\#} \mathrm{P}<0.05$ vs. lipopolysaccharide (LPS)/peptidoglycan $\mathrm{G}$ (PepG) group.

analysis. As shown in Fig. 3, the mRNA and protein expression of UCP2 was enhanced by treatment with LPS/PepG. Compared with the controls, sepsis caused a 1.4-fold increase in UCP2 mRNA levels and a 1.3-fold increase in UCP2 protein levels following treatment with $\mathrm{LPS} / \mathrm{PepG}$ or saline $(\mathrm{P}<0.05$; Fig. 3). To determine the role of UCP2 in cardiomyocytes under septic conditions, the septic $\mathrm{H} 9 \mathrm{C} 2$ cells were transfected with siRNA to suppress UCP2 expression. Compared with the LPS/PepG group, siRNA induced a 0.22-fold decrease in UCP2 protein expression and a 0.59 -fold decrease in UCP2 mRNA expression ( $\mathrm{P}<0.05$; Fig. 3). As shown in Fig. 3, ncRNA had no effect on UCP2 mRNA or protein expression in the H9C2 cells under septic conditions $(\mathrm{P}>0.05)$.

MMP (or $\Delta \Psi m$ ) in H9C2 cells under septic conditions. JC-1 aggregates in the mitochondria emit red fluorescence (Fig. 4A and B, panel a). For a more objective understanding of MMP, confocal microscopy and FCM were both used to detect $\Delta \Psi \mathrm{m}$. Treatment of the H9C2 cells with LPS/PepG for $24 \mathrm{~h}$ resulted in the dissipation of MMP, which was shown as increased green fluorescence (Fig. 4A and B, panel b) by JC-1 staining. To further elucidate the role of UCP2 in cardiomyocytes under septic conditions, the H9C2 cells pre-treated with LPS/PepG were transfected with ncRNA or siRNA. The red fluorescence intensity in the LPS/PepG group (Fig. 4A and B, panel b) was weaker than that in the LPS/PepG + siRNA group (Fig. 4A and B, panel d), but was similar to that in the LPS/PepG + ncRNA group (Fig. 4A and B, panel c). CCCP renders the mitochondrial innermembrane permeable to protons and causes the dissipation of the proton gradient across the inner mitochondrial membrane (Fig. 4A and B, panel e). To quantify the changes in MMP, the ratio of red fluorescence intensity to the green fluorescence intensity as shown by FCM was determined (Fig. 4C). In the control group, the ratio was $0.429 \pm 0.071$, while the LPS/PepG-treated cells showed a lower ratio $(0.222 \pm 0.038, \mathrm{P}<0.05$, vs. the control group, $n=3$ ) indicating the dissipation of $\Delta \Psi \mathrm{m}$ in the H9C2 cells under septic conditions. The H9C2 cells transfected 

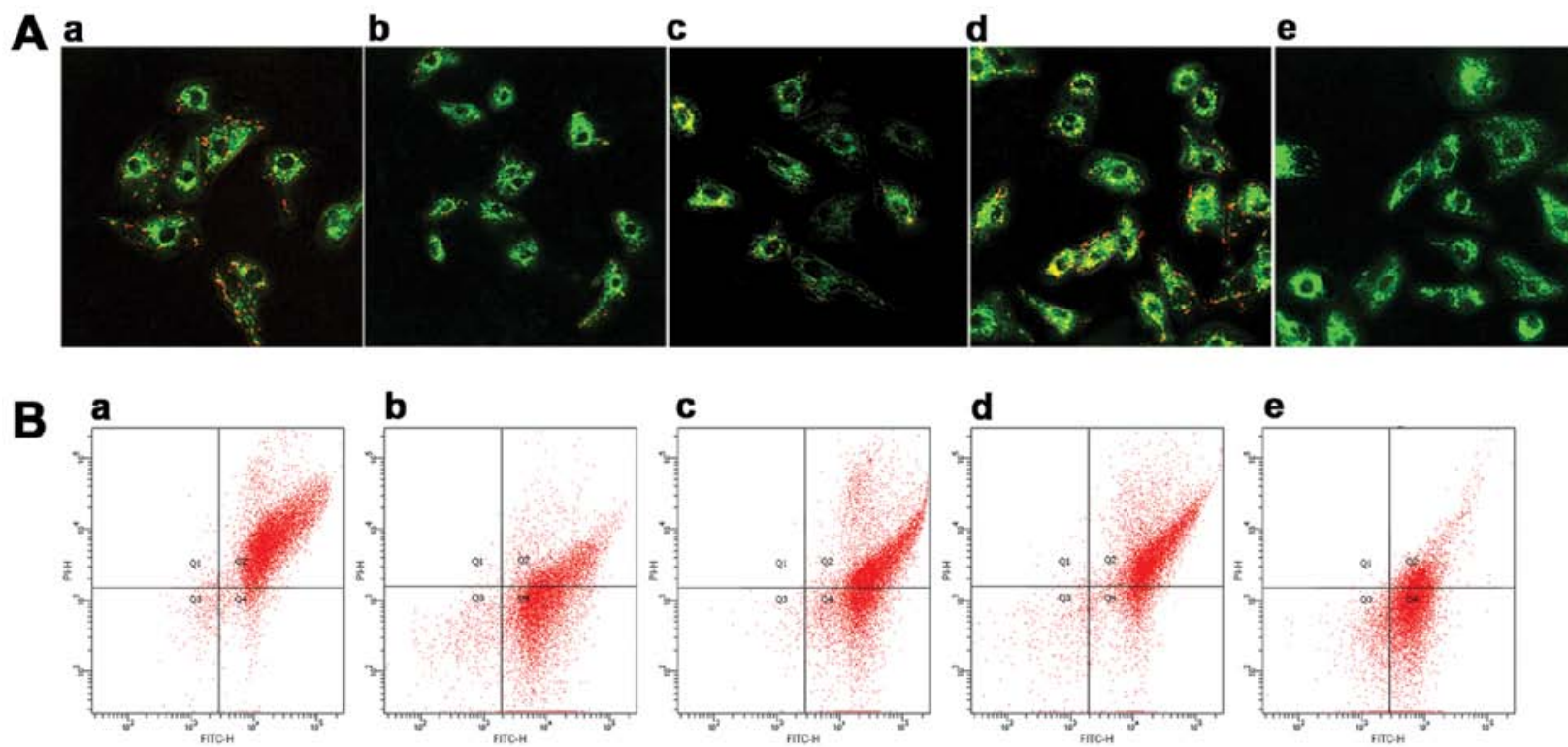

b

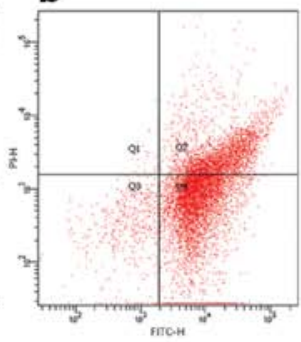

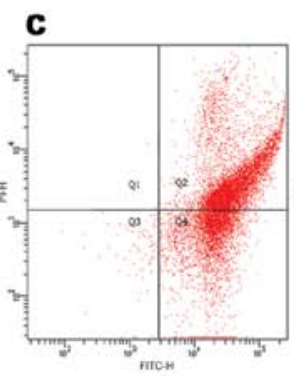
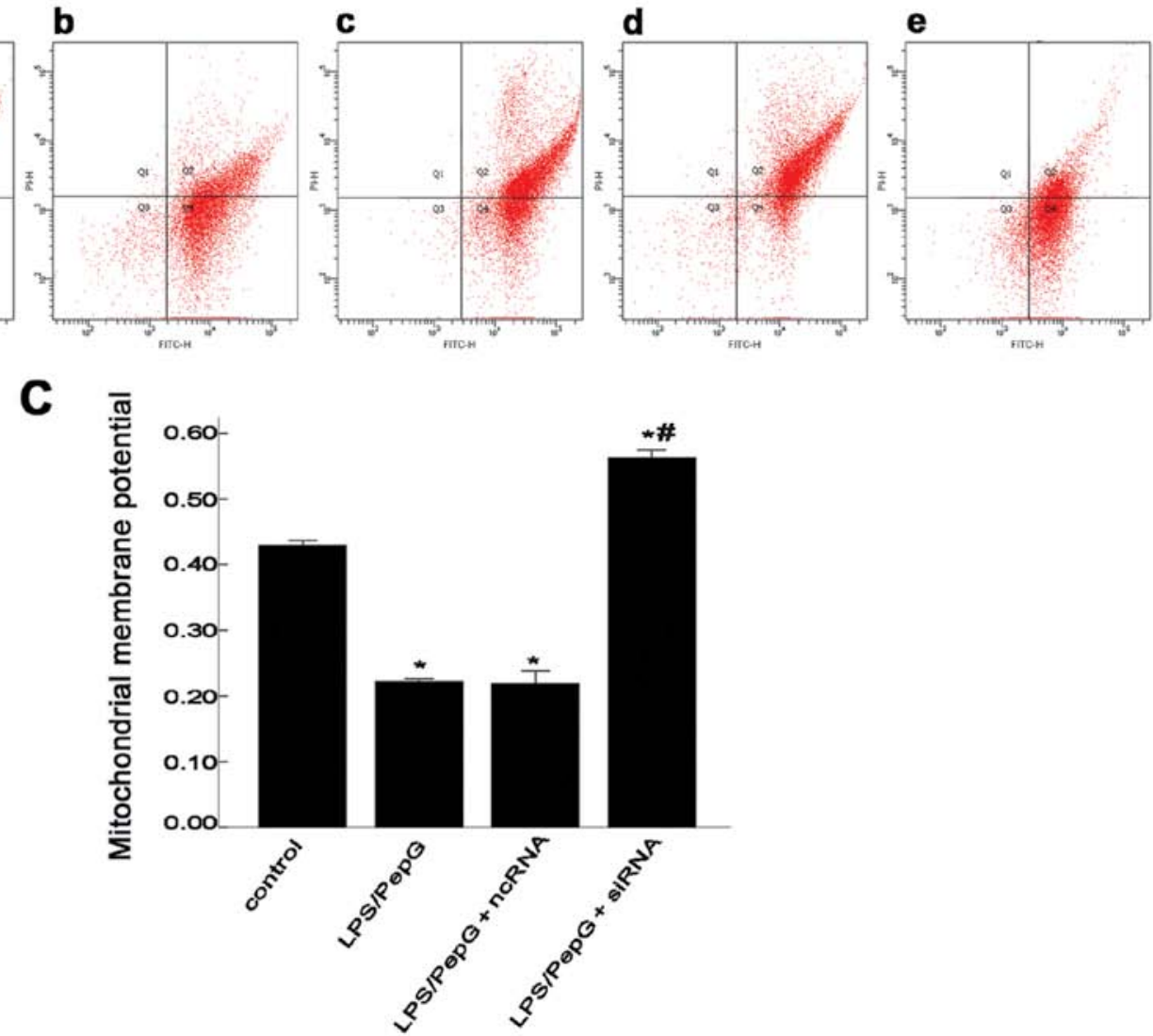

Figure 4. Effect of siRNA on mitochondrial membrane potential (MMP or $\triangle \Psi \mathrm{m}$ ) in H9C2 cells under septic conditions. (A) Scanning of MMP in H9C2 cells using a confocal microscope. Green fluorescence represents the monomeric form of the JC-1 molecule, which appears in the cytosol after mitochondrial membrane depolarization. Red fluorescence reveals the mitochondrial aggregate form of JC-1, indicating MMP (magnification, $\mathrm{x} 40$ ). (B) Evaluation of MMP in H9C2 cells by flow cytometry (FCM). FITC-H, green; PI-H, red. (A and B) Panel a, control group; panel b, lipopolysaccharide (LPS)/peptidoglycan G (PepG) group; panel c, LPS/PepG + negative control siRNA (ncRNA) group; panel d, LPS/PepG + siRNA group; panel e, carbonyl cyanide m-chlorophenylhydrazone (CCCP)-treated cells. (C) The ratio of the red over the green fluorescence intensity by FCM represents the quantitative MMP in each group. Values are expressed as the means $\pm \mathrm{SD}$. ${ }^{*} \mathrm{P}<0.05$ vs. control. ${ }^{*} \mathrm{P}<0.05$ vs. $\mathrm{LPS} / \mathrm{PepG}$ group. $\mathrm{n}=3$ per group.

with $\mathrm{LPS} / \mathrm{PepG}+$ siRNA demonstrated a rebound in the $\Delta \Psi \mathrm{m}(0.563 \pm 0.121, \mathrm{P}<0.05$, vs. LPS/PepG group, $\mathrm{n}=3)$, while treatment with $\mathrm{LPS} / \mathrm{PepG}+$ ncRNA had no effect on $\Delta \Psi \mathrm{m}$ $(0.219 \pm 0.197, \mathrm{P}>0.05$, vs. LPS/PepG group, $\mathrm{n}=3)$.

Mitochondrial morphology and swelling in H9C2 cells under septic conditions. In an aim to understand the mitochondrial structure more objectively, the mitochondrial ultrastructure was scanned by TEM and the quantitative degree of mitochondrial swelling was detected by FCM. Fifteen electron micrographs were prepared for each specimen and in each micrograph, 15 mitochondria were randomly selected. The ultrastructure of the mitochondria was normal in the control group, while mitochondrial swelling and vacuolization, loss of matrix and the disruption of crests were detected in the LPS/PepG-treated cells (with or without siRNA and ncRNA transfection). Compared with the LPS/PepG group, the mitochondrial ultrastructure was damaged more severely in the LPS/PepG + siRNA group in which megamitochondria were also frequently observed (Fig. 5A). Using FCM with appropriate settings, the FSC-SSC parameters were determined in the mitochondria. FSC highly correlates with cell size or volume and SSC is related to granularity and the refractive index (Fig. 5B). The quantitive degree of mitochondrial swelling was represented by the FSC/SSC ratio. The FSC/SSC ratio was $1.119 \pm 0.016$ in the $\mathrm{LPS} / \mathrm{PepG}$ group and $1.737 \pm 0.029$ in the LPS/PepG + siRNA group. Both were markedly higher than that of the control group $(0.882 \pm 0.012, \mathrm{P}<0.05, \mathrm{n}=3$; 


\section{A a}

b

C

d

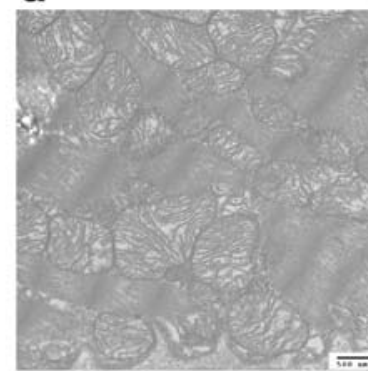

c

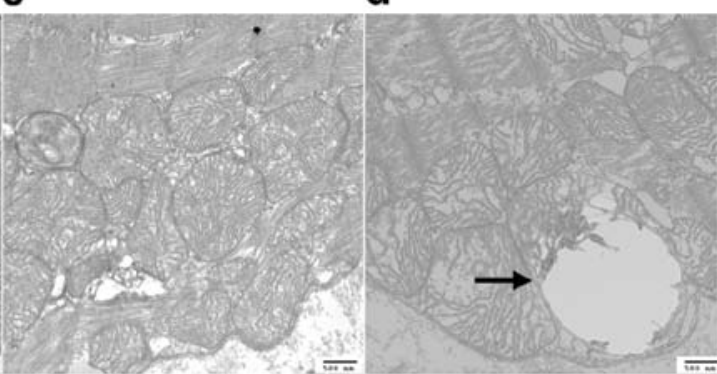

B
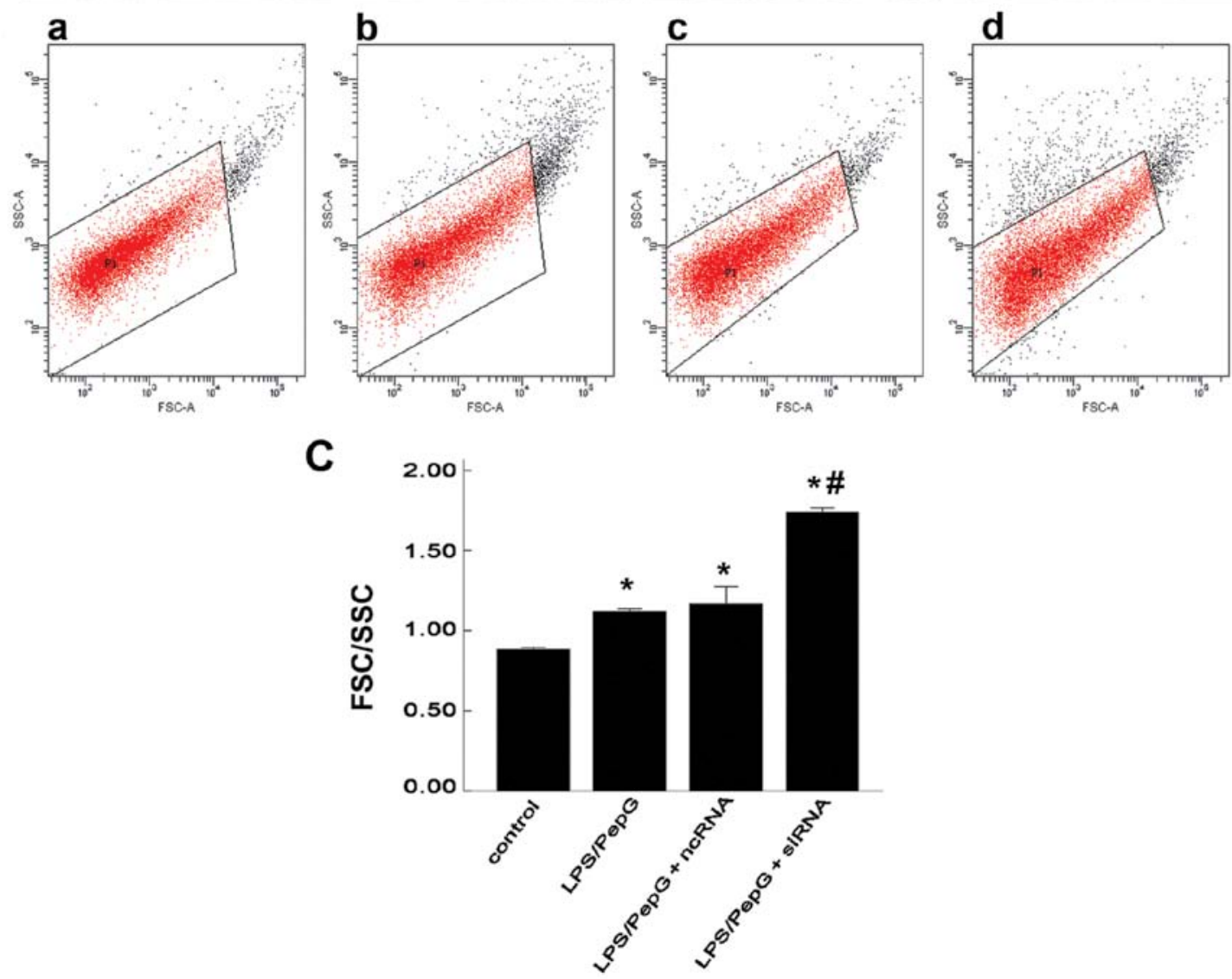

Figure 5. Effect of siRNA on mitochondrial morphology in $\mathrm{H} 9 \mathrm{C} 2$ cells under septic conditions. (A) Scanning of H9C2 cell mitochondrial ultrastructure using a transmission electron microscope. Panel a, normal mitochondrial ultrastructure; panels b-d, swelling and vacuolization of mitochondria; panel d, megamitochondria (arrow); (original magnification, x30,000). (B) Flow cytometric determination of size [forward scatter (FSC)] and structure [side scatter (SSC)] of mitochondria in H9C2 cells. (A and B) Panels a-d, the control, LPS/PepG, LPS/PepG + negative control siRNA (ncRNA) and LPS/PepG + siRNA group, respectively (C) Quantitative evaluation of mitochondrial swelling by flow cytometry (FCM). The FSC/SSC ratio represents the degree of mitochondrial swelling. Values are expressed as the means $\pm \mathrm{SD}$. ${ }^{*} \mathrm{P}<0.05$ vs. control group. ${ }^{*} \mathrm{P}<0.05$ vs. lipopolysaccharide (LPS)/peptidoglycan $\mathrm{G}$ (PepG) group. $\mathrm{n}=3$ per group.

Fig. 5C). Compared with the LPS/PepG group, treatment with LPS/PepG + siRNA induced a 1.6-fold increase in the FSC/SSC ratio $(\mathrm{P}<0.05, \mathrm{n}=3)$, while $\mathrm{LPS} / \mathrm{PepG}+\mathrm{ncRNA}$ had no effect on this ratio $(1.160 \pm 0.110, \mathrm{P}>0.05$, vs. $\mathrm{LPS} / \mathrm{PepG}$ group, n=3; Fig. 5C).

Effect of siRNA on intracellular ROS and ATP levels, and mtDNA copy numbers. To elucidate the role of UCP2 in mitochondrial function, intracellular ROS and cellular ATP levels and mtDNA copy numbers were detected. DCFH-DA is a fluorescent probe of ROS. Intracellular ROS production was observed using a fluorescence microscope and quantified using a multifunctional microplate reader with DCFH-DA. The DCF fluorescence intensity was significantly higher in the LPS/PepG, LPS/PepG + ncRNA and LPS/PepG + siRNA groups than that in the control group $(2.50 \pm 0.10,2.49 \pm 0.08$, $3.28 \pm 0.17$, respectively vs. $1.00 \pm 0.12, \mathrm{~F}=183.8, \mathrm{P}<0.05, \mathrm{n}=3$; Fig. 6A and B), indicating an enhanced production of ROS stimulated by LPS/PepG. The DCF fluorescence intensity in the LPS/PepG + siRNA group was notably increased compared with that in the LPS/PepG group (3.28 \pm 0.17 vs. $1.00 \pm 0.12$, $\mathrm{P}<0.05, \mathrm{n}=3$; Fig. 6B). To further determine the effects of siRNA on mitochondrial function, indicators of mitochondrial activity, such as the levels of cellular ATP and mtDNA copy numbers were determined. After $24 \mathrm{~h}$ of exposure to LPS/PepG, the cellular ATP content was significantly decreased in the LPS/PepG, LPS/PepG + ncRNA and LPS/PepG + siRNA groups compared with the control group $(2.643 \pm 0.076$, 

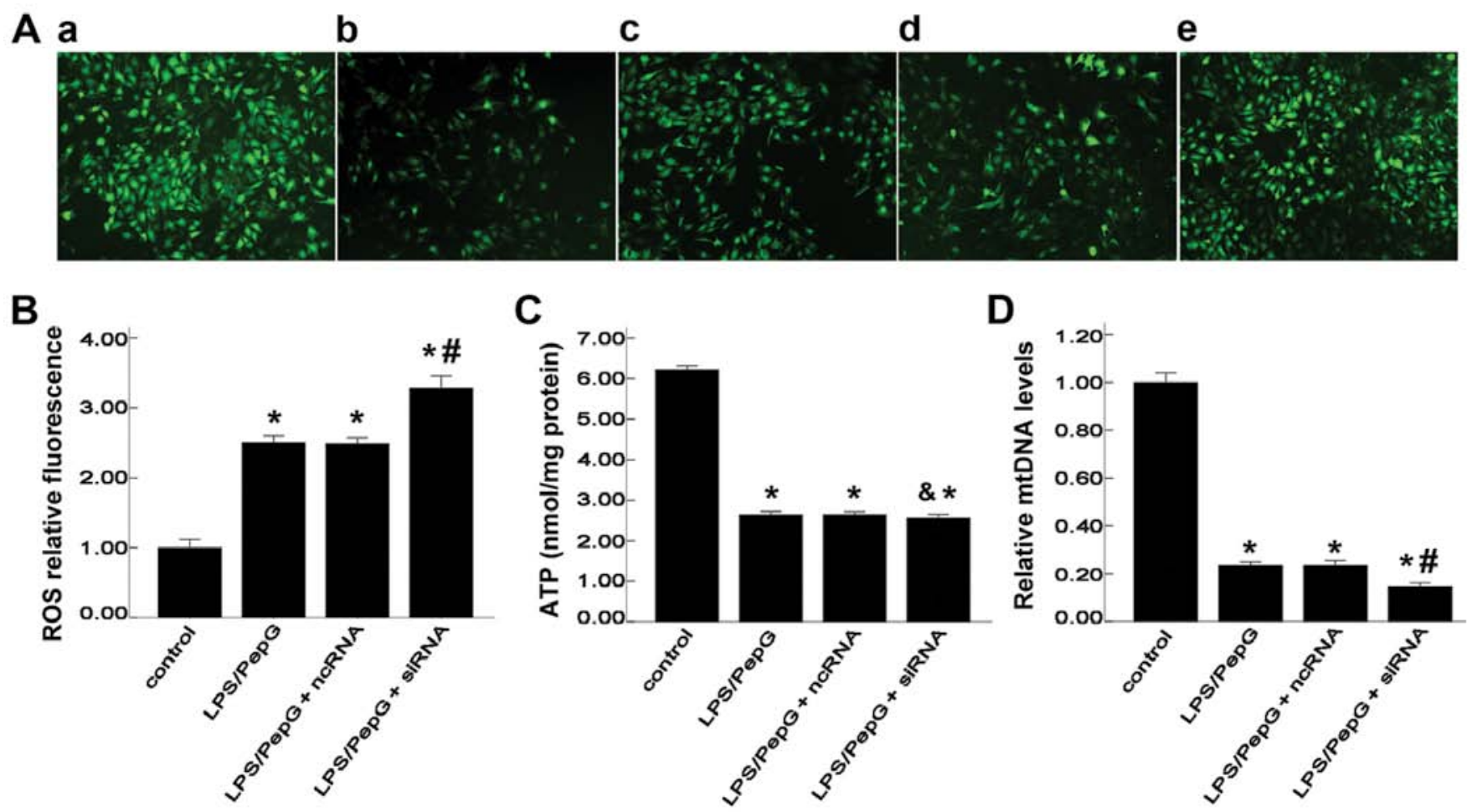

Figure 6. Effect of siRNA on intracellular reactive oxygen species (ROS) production, adenosine triphosphate (ATP) levels and mitochondrial DNA (mtDNA) copy numbers. The fluorescence intensity of DCF in $\mathrm{H} 9 \mathrm{C} 2$ cells represented the production of intracellular ROS. (A) Changes in ROS production measured as the DCF fluorescence under a fluorescence microscope (magnification, x10); Panels a-e, ROS-positive control cells (Rosup), control, lipopolysaccharide (LPS)/peptidoglycan G (PepG), LPS/PepG + negative control siRNA (ncRNA) and LPS/PepG + siRNA group, respectively. (B) DCF fluorescence was read by a multifunctional microplate reader at an excitation wavelength of $488 \mathrm{~nm}$ and at an emission wavelength of $525 \mathrm{~nm}$. (C) Cellular ATP expressed as nmol/mg protein was measured using a firefly luciferase-based ATP assay kit. RLU values were measured by a microplate reader. (D) Relative mtDNA copy numbers were detected by real-time PCR with normalization to 18 s RNA. Values are expressed as the means $\pm \mathrm{SD}$. ${ }^{*} \mathrm{P}<0.05$ vs. control group. ${ }^{\mathrm{B}} \mathrm{P}<0.05$, ${ }^{\&} \mathrm{P}>0.05$ vs. LPS/PepG group. $n=3$ per group.

$2.647 \pm 0.065,2.560 \pm 0.092$, respectively, vs. $6.220 \pm 0.105$, $\mathrm{F}=1322.6, \mathrm{P}<0.05, \mathrm{n}=3$; Fig. 6C). However, compared with the LPS/PepG group, ncRNA or siRNA had no effect on the ATP levels in the H9C2 cells under septic conditions $(\mathrm{P}>0.05$; Fig. 6C). Cellular mtDNA is also a sensitive indicator of mitochondrial function. The mtDNA copy numbers in the LPS/PepG group were significantly lower than those of the control group $(0.233 \pm 0.153$ vs. $1.000 \pm 0.040, \mathrm{P}<0.05, \mathrm{n}=3$; Fig. 6D). The mtDNA copy numbers in the LPS/PepG + siRNA group were significantly decreased compared with those in the LPS/PepG group $(0.147 \pm 0.152$ vs. $0.233 \pm 0.153, \mathrm{P}<0.05$, $n=3$; Fig. 6D). However, the mtDNA copy numbers in the LPS/PepG + ncRNA group did not differ from those in the LPS/PepG group $(0.233 \pm 0.201$ vs. $0.233 \pm 0.153, \mathrm{P}>0.05, \mathrm{n}=3$; Fig. 6D).

\section{Discussion}

The principal findings of the current study are as follows: i) treatment with LPS/PepG severely damaged the H9C2 cells and initiated an inflammatory response, indicating that the cell model of sepsis was successfully created; ii) siRNA downregulated the expression of $\mathrm{UCP} 2$ at the transcriptional and translational level, indicating that UCP2 deficiency in the cells was successfully established; and iii) during sepsis, siRNA aggravated the injury to mitochondrial structure and eventually led to the dysfunction of the mitochondrion, demonstrating that $\mathrm{UCP} 2$ may play a protective role in the mitochondria in $\mathrm{H} 9 \mathrm{C} 2$ cells under septic conditions. In brief, these findings support the hypothesis that UCP2 plays an important and protective role in cardiomyocytes under septic conditions.

This study demonstrates that the cell wall component, PepG, derived from the pathogenic Gram-positive bacterium, Micrococcus luteus, synergizes with LPS to damage H9C2 cells and causes the release of IL-6 and TNF- $\alpha$ in vitro. Sepsis is not only an unresolved problem in the medical field, but also a very serious threat to human health. Previous studies have created a number of models of sepsis in vivo, but few cellular models of sepsis have been created (23-25). LPS or LPS plus PepG are often used to induce sepsis in various cells which mimics models of sepsis in vitro. The significant increase in the levels of CK, LDH, TNF- $\alpha$ and IL- 6 in our study indicated that the $\mathrm{H} 9 \mathrm{C} 2$ cell model of sepsis had been created successfully. UCP2 is a member of the UCP family and is highly expressed in a number of tissues. Our previous study demonstrated that UCP2 expression was upregulated in the septic myocardium (unpublished data). To further determine whether $\mathrm{UCP} 2$ plays a protective role in the myocardium under septic conditions, we used siRNA to reduce the mRNA level of UCP2 by up to $69 \%$ in the current study. Our findings indicated that the silencing of UCP2 resulted in damage to the H9C2 cells, an increased release of TNF- $\alpha$, the disruption of mitochondrial 
morphology, the rebound of MMP, enhanced ROS generation, as well as a reduction in cellular ATP levels and mtDNA copy numbers in the $\mathrm{H} 9 \mathrm{C} 2$ cells under septic conditions.

MMP is dependent on the speed of proton pumping generated from the transport of electrons and protons. MMP reflects the performance of the electron transport chain (ETC) and this is often used as an indicator of the pathological disorder of the mitochondrion. As previously demonstrated, cells treated with LPS show a disruption of the MMP, which is a critical event in lethal cell damage $(26,27)$. In this study, treatment with LPS/PepG induced the disruption of the MMP in the H9C2 cells and the silencing of UCP2 resulted in a marked rebound of MMP under septic conditions, which was consistent with the results of our previous study using a model of sepsis (unpublished data) and other models in vitro $(27,28)$. The meaning of uncoupling is the collapse of the MMP by proton leakage through the mitochondrial membrane. UCPs, including UCP2 can disperse mitochondrial proton gradient to stabilize the inner MMP, so they are closely related to the MMP. For example, under MPP ${ }^{+}$toxicity, UCP4 overexpression preserves ATP levels and MMP (29); the overexpression of UCP5 in neuronal cells can preserve the MMP, ATP levels and cell survival (30). Previous studies have demonstrated that MMP and ROS interact with each other $(11,12,28)$.

Mitochondrial sources of ROS are considered as a basic cause of oxidant damage to the heart during sepsis, and they may underlie the pivotal mechanisms related to cardioprotection in the myocardium (31). Previous studies (32-34) have demonstrated that a slight degree of depolarization within the inner membrane of the mitochondria may play a protective role by attenuating ROS production. In the present study, the silencing of UCP2 by siRNA was associated with a relative increase in ROS production and a significant rebound in MMP during sepsis, which is consistent with uncoupling mechanisms (35). In UCP2 knockout mice, increased MMP production has been shown to cause vascular remodeling partially through increased ROS production (28). In vivo, previous neuronal studies have found that the overexpression of human UCP2 is associated with increased uncoupling and decreased ROS production, indicating that UCP2 plays a protective role $(11,12,36)$. Our present finding that the silencing of UCP2 leads an increase in MMP and ROS production during sepsis suggests that UCP2 plays a protective effect in septic cardiomyocytes.

Compared with nDNA, mtDNA is more susceptible to oxidative damage, as the DNA repair capacity in the mitochondria is incomplete and mitochondria are an important source of ROS (37). ROS can oxidatively impair mitochondrial mtDNA $(38,39)$ and trigger mtDNA deletions which can damage the synthesis of the mtDNA-encoded proteins of respiratory chain complexes I-V (40). In the current study, treatment with LPS/PepG resulted in damage to mtDNA and the overproduction of ROS which was not reversed by siUCP2, indicating that UCP2 may be a protective factor in cardiomyocytes under septic contitions. In vivo, LPS had been shown to cause mtDNA damage (41) which can activate the immune system and may contribute to SIRS and compromise organ function in a number of diseases (42-44). Research on the association between UCP2 and mtDNA in sepsis is limited, and the possible explanation of our finding is that the silencing of UCP2 through the alteration in ROS production, uncoupling activity and MMP, eventually leads to the deletion of mtDNA under septic conditions.

Apart from ROS and mtDNA, cellular ATP is another indicator of mitochondrial function. The mitochondria are the major source of ATP, which is the only universal energy-yielding currency in cells. ATP synthesis relies on the coupling of electron transport through the ETC to the proton motive force (45)

The coupling procedure is regulated by proton leakage through the mitochondrial inner membrane which is partly mediated by UCP2. However, the precise mechanisms through which UCP2 modulates this process continue to be a matter of debate. It has been demonstrated that UCP2 activity may lead to decreased ATP availability (46-49), although others believe that the overexpression of UCP2 results in elevated levels of tissue ATP (50-52). The association between UCP2 and ATP ramains debatable. In this study, sepsis damaged the H9C2 cells and led to low levels of ATP, while the silencing of UCP2 had no significant effect on the ATP levels $(\mathrm{P}>0.05)$. The alternative explanation may be that LPS/PepG is far more important than UCP2 in affecting the ATP level or UCP2 primarily has no effect on ATP in H9C2 cells under septic conditions.

To obtain more credible results, TEM was used for qualitative analysis and FCM was used for quantitative analysis. Our findings suggest that, under septic conditions, mitochondrial dysfunction increases oxidative stress, induces the collapse of the MMP and the deletion of mtDNA, which can, in turn, lead to mitochondrial swelling and damage to mitochondrial morphology. The silencing of UCP2 aggravated the degree of mitochondrial swelling and damage to mitochondrial morphology, indicating that UCP2 may be a protective factor in cells under septic conditions. There may be other explanations for the changes in mitochodrial swelling and morphology observed in this study. For example, the change in the $\mathrm{Ca}^{2+}$ concentration (53), intracellular ion levels (54), the status of mitochondrial pore $(55,56)$, which regrettably were not detected in the current study; these may also affect the mitochondrial morphology and function. It is a pity that we only used siRNA for the study of UCP2 function in cardiomyocytes under septic conditions. To further clarify the association between UCP2 and mitochondrial function and to confirm the hypothesis that UCP2 may play a protective role during sepsis, the effects of the overexpression of UCP2 in H9C2 cells should be examined.

In brief, our study demonstrates that treatment with LPS/PepGn induces mitochondrial dysfunction in H9C2 cells and that the silencing of UCP2 by siRNA aggravates the damage to mitochondrial morphology and function, indicating that UCP2 may play a protective role in cardiomyocytes under septic conditions.

\section{Acknowledgements}

The current study was supported by the National Natural Science Foundation of China (grant no. 81272070).

\section{References}

1. Weycker D, Akhras KS, Edelsberg J, Angus DC and Oster G: Long-term mortality and medical care charges in patients with severe sepsis. Crit Care Med 31: 2316-2323, 2003. 
2. Fernandes CJ Jr, Akamine $\mathrm{N}$ and Knobel E: Cardiac troponin: A new serum marker of myocardial injury in sepsis. Intensive Care Med 25: 1165-1168, 1999.

3. Blanco J, Muriel-Bombín A, Sagredo V, Taboada F, Gandía F, Tamayo L, Collado J, García-Labattut A, Carriedo D, Valledor M, et al; Grupo de Estudios y Análisis en Cuidados Intensivos (G.R.E.C.I.A.): Incidence, organ dysfunction and mortality in severe sepsis: A Spanish multicentre study. Crit Care 12: R158, 2008.

4. Soriano FG, Nogueira AC, Caldini EG, Lins MH, Teixeira AC, Cappi SB, Lotufo PA, Bernik MM, Zsengellér Z, Chen M and Szabó C: Potential role of poly(adenosine 5'-diphosphate-ribose) polymerase activation in the pathogenesis of myocardial contractile dysfunction associated with human septic shock. Crit Care Med 34: 1073-1079, 2006.

5. Romero-Bermejo FJ, Ruiz-Bailen M, Gil-Cebrian J and Huertos-Ranchal MJ: Sepsis-induced cardiomyopathy. Curr Cardiol Rev 7: 163-183, 2011.

6. Parrillo JE, Parker MM, Natanson C, Suffredini AF, Danner RL, Cunnion RE and Ognibene FP: Septic shock in humans. Advances in the understanding of pathogenesis, cardiovascular dysfunction, and therapy. Ann Intern Med 113: 227-242, 1990.

7. Levy RJ: Mitochondrial dysfunction, bioenergetic impairment, and metabolic down-regulation in sepsis. Shock 28: 24-28, 2007

8. Watts JA, Kline JA, Thornton LR, Grattan RM and Brar SS: Metabolic dysfunction and depletion of mitochondria in hearts of septic rats. J Mol Cell Cardiol 36: 141-150, 2004.

9. Arsenijevic D, Onuma H, Pecqueur C, Raimbault S, Manning BS, Miroux B, Couplan E, Alves-Guerra MC, Goubern M, Surwit R, et al: Disruption of the uncoupling protein-2 gene in mice reveals a role in immunity and reactive oxygen species production. Nat Genet 26: 435-439, 2000

10. Krauss S, Zhang CY and Lowell BB: A significant portion of mitochondrial proton leak in intact thymocytes depends on expression of UCP2. Proc Natl Acad Sci USA 99: 118-122, 2002

11. Diano S, Matthews RT, Patrylo P, Yang L, Beal MF, Barnstable CJ and Horvath TL: Uncoupling protein 2 prevents neuronal death including that occurring during seizures: A mechanism for preconditioning. Endocrinology 144: 5014-5021, 2003.

12. Mattiasson G, Shamloo M, Gido G, Mathi K, Tomasevic G, Yi S Warden CH, Castilho RF, Melcher T, Gonzalez-Zulueta M, et al Uncoupling protein-2 prevents neuronal death and diminishes brain dysfunction after stroke and brain trauma. Nat Med 9: 1062-1068, 2003.

13. Conti B, Sugama S, Lucero J, Winsky-Sommerer R, Wirz SA Maher P, Andrews Z, Barr AM, Morale MC, Paneda C, et al: Uncoupling protein 2 protects dopaminergic neurons from acute 1,2,3,6-methyl-phenyl-tetrahydropyridine toxicity. J Neurochem 93: 493-501, 2005.

14. Donadelli M, Dando I, Fiorini C and Palmieri M: UCP2, a mitochondrial protein regulated at multiple levels. Cell Mol Life Sci 71: 1171-1190, 2014

15. Le Minh K, Kuhla A, Abshagen K, Minor T, Stegemann J, Ibrahim S, Eipel C and Vollmar B: Uncoupling protein-2 deficiency provides protection in a murine model of endotoxemic acute liver failure. Crit Care Med 37: 215-222, 2009.

16. CarriónJ,AbengozarMA,Fernández-ReyesM,Sánchez-MartínC, Rial E, Domínguez-Bernal G and González-Barroso MM: UCP2 deficiency helps to restrict the pathogenesis of experimental cutaneous and visceral leishmaniosis in mice. PLoS Negl Trop Dis 7: e2077, 2013.

17. Faggioni R, Shigenaga J, Moser A, Feingold KR and Grunfeld C: Induction of UCP2 gene expression by LPS: A potential mechanism for increased thermogenesis during infection. Biochem Biophys Res Commun 244: 75-78, 1998.

18. Roshon MJ, Kline JA, Thornton LR and Watts JA: Cardiac UCP2 expression and myocardial oxidative metabolism during acute septic shock in the rat. Shock 19: 570-576, 2003.

19. Lecoeur H, Langonné A, Baux L, Rebouillat D, Rustin P, Prévost MC, Brenner C, Edelman L and Jacotot E: Real-time flow cytometry analysis of permeability transition in isolated mitochondria. Exp Cell Res 294: 106-117, 2004.

20. Han XZ, Gao S, Cheng YN, Sun YZ, Liu W, et al: Protective effect of naringenin-7-O-glucoside against oxidative stress induced by doxorubicin in H9c2 cardiomyocytes. Biosci Trends 6: 19-25, 2012.

21. Zhu L, Wei T, Chang X, He H, Gao J, et al: Effects of salidroside on myocardial injury in vivo in vitro via regulation of Nox/NF-kappaB/AP1 pathway. Inflammation: Feb 15, 2015 (Epub ahead of print)
22. Wang SG, Xu Y, Xie H, Wang W, Chen XH: Astragaloside IV prevents lipopolysaccharide-induced injury in H9C2 cardiomyocytes. Chin J Nat Med 13: 127-132

23. Wray GM, Foster SJ, Hinds CJ and Thiemermann C: A cell wall component from pathogenic and non-pathogenic gram-positive bacteria (peptidoglycan) synergises with endotoxin to cause the release of tumour necrosis factor-alpha, nitric oxide production, shock, and multiple organ injury/dysfunction in the rat. Shock 15: 135-142, 2001

24. Lowes DA, Thottakam BM, Webster NR, Murphy MP and Galley HF: The mitochondria-targeted antioxidant MitoQ protects against organ damage in a lipopolysaccharide-peptidoglycan model of sepsis. Free Radic Biol Med 45: 1559-1565, 2008

25. Lowes DA, Almawash AM, Webster NR, Reid VL and Galley HF: Melatonin and structurally similar compounds have differing effects on inflammation and mitochondrial function in endothelial cells under conditions mimicking sepsis. Br J Anaesth 107: 193-201, 2011.

26. Cregan SP, Dawson VL and Slack RS: Role of AIF in caspasedependent and caspase-independent cell death. Oncogene 23: 2785-2796, 2004

27. Kim YC, Song SB, Lee MH, Kang KI, Lee H, Paik SG, Kim KE and Kim YS: Simvastatin induces caspase-independent apoptosis in LPS-activated RAW264.7 macrophage cells. Biochem Biophys Res Commun 339: 1007-1014, 2006.

28. Pak O, Sommer N, Hoeres T, Bakr A, Waisbrod S, Sydykov A, Haag D, Esfandiary A, Kojonazarov B, Veit F, et al: Mitochondrial hyperpolarization in pulmonary vascular remodeling. Mitochondrial uncoupling protein deficiency as disease model. Am J Respir Cell Mol Biol 49: 358-367, 2013.

29. Chu AC, Ho PW, Kwok KH, Ho JW, Chan KH, Liu HF, Kung MH, Ramsden DB and Ho SL: Mitochondrial UCP4 attenuates $\mathrm{MPP}^{+}$- and dopamine-induced oxidative stress, mitochondrial depolarization, and ATP deficiency in neurons and is interlinked with UCP2 expression. Free Radic Biol Med 46: 810-820, 2009.

30. Kwok KH, Ho PW, Chu AC, Ho JW, Liu HF, Yiu DC, Chan KH, Kung MH, Ramsden DB and Ho SL: Mitochondrial UCP5 is neuroprotective by preserving mitochondrial membrane potential, ATP levels, and reducing oxidative stress in $\mathrm{MPP}^{+}$and dopamine toxicity. Free Radic Biol Med 49: 1023-1035, 2010.

31. Halestrap AP, Clarke SJ and Khaliulin I: The role of mitochondria in protection of the heart by preconditioning. Biochim Biophys Acta 1767: 1007-1031, 2007.

32. Korshunov SS, Skulachev VP and Starkov AA: High protonic potential actuates a mechanism of production of reactive oxygen species in mitochondria. FEBS Lett 416: 15-18, 1997.

33. Kowaltowski AJ, Castilho RF and Vercesi AE: Mitochondrial permeability transition and oxidative stress. FEBS Lett 495: 12-15, 2001

34. Brookes PS: Mitochondrial H(+) leak and ROS generation: An odd couple. Free Radic Biol Med 38: 12-23, 2005.

35. Lambert AJ and Brand MD: Superoxide production by NADH:ubiquinone oxidoreductase (complex I) depends on the $\mathrm{pH}$ gradient across the mitochondrial inner membrane. Biochem J 382: 511-517, 2004.

36. Andrews ZB, Horvath B, Barnstable CJ, Elsworth J, Yang L, Beal MF, Roth RH, Matthews RT and Horvath TL: Uncoupling protein-2 is critical for nigral dopamine cell survival in a mouse model of Parkinson's disease. J Neurosci 25: 184-191, 2005

37. Yakes FM and Van Houten B: Mitochondrial DNA damage is more extensive and persists longer than nuclear DNA damage in human cells following oxidative stress. Proc Natl Acad Sci USA 94: 514-519, 1997.

38. Wieland $\mathrm{P}$ and Lauterburg $\mathrm{BH}$ : Oxidation of mitochondrial proteins and DNA following administration of ethanol. Biochem Biophys Res Commun 213: 815-819, 1995.

39. Larosche I, Lettéron P, Berson A, Fromenty B, Huang TT, Moreau R, Pessayre D and Mansouri A: Hepatic mitochondrial DNA depletion after an alcohol binge in mice: Probable role of peroxynitrite and modulation by manganese superoxide dismutase. J Pharmacol Exp Ther 332: 886-897, 2010.

40. Coleman WB and Cunningham CC: Effects of chronic ethanol consumption on the synthesis of polypeptides encoded by the hepatic mitochondrial genome. Biochim Biophys Acta 1019: 142-150, 1990.

41. Choumar A, Tarhuni A, Lettéron P, Reyl-Desmars F, Dauhoo N, Damasse J, Vadrot N, Nahon P, Moreau R, Pessayre D and Mansouri A: Lipopolysaccharide-induced mitochondrial DNA depletion. Antioxid Redox Signal 15: 2837-2854, 2011. 
42. Zhang Q, Raoof M, Chen Y, Sumi Y, Sursal T, Junger W, Brohi K, Itagaki K and Hauser CJ: Circulating mitochondrial DAMPs cause inflammatory responses to injury. Nature 464: 104-107, 2010.

43. Kohler C, Radpour R, Barekati Z, Asadollahi R, Bitzer J, Wight E, Bürki N, Diesch C, Holzgreve W and Zhong XY: Levels of plasma circulating cell free nuclear and mitochondrial DNA as potential biomarkers for breast tumors. Mol Cancer 8: 105, 2009.

44. Cossarizza A, Pinti M, Nasi M, Gibellini L, Manzini S, Roat E, De Biasi S, Bertoncelli L, Montagna JP, Bisi L, et al: Increased plasma levels of extracellular mitochondrial DNA during HIV infection: A new role for mitochondrial damage-associated molecular patterns during inflammation. Mitochondrion 11: 750-755, 2011.

45. Hosler JP, Ferguson-Miller S and Mills DA: Energy transduction: Proton transfer through the respiratory complexes. Annu Rev Biochem 75: 165-187, 2006.

46. Parton LE, Ye CP, Coppari R, Enriori PJ, Choi B, Zhang CY $\mathrm{Xu}$ C, Vianna CR, Balthasar N, Lee CE, et al: Glucose sensing by POMC neurons regulates glucose homeostasis and is impaired in obesity. Nature 449: 228-232, 2007.

47. Chavin KD, Yang S, Lin HZ, Chatham J, Chacko VP, Hoek JB, Walajtys-Rode E, Rashid A, Chen CH, Huang CC, et al: Obesity induces expression of uncoupling protein-2 in hepatocytes and promotes liver ATP depletion. J Biol Chem 274: 5692-5700, 1999

48. Serviddio G, Bellanti F, Tamborra R, et al: HNE induces UCP2 expression and proton leak to limit oxidative stress but reduces ATP synthesis in non-alcoholic steatohepatitis. Free Radic Res 41: S55-S55, 2007.

49. Brar SS and Martin WJ II: Bleomycin upregulates UCP2 mRNA expression, decreases ATP levels and induces apoptosis in alveolar epithelial cells. American Thoracic Society International Conference Abstracts 179: C68. Alveolar Epithelium, abs. A5002, 2009.
50. Andrews ZB, Diano S and Horvath TL: Mitochondrial uncoupling proteins in the CNS: In support of function and survival. Nat Rev Neurosci 6: 829-840, 2005.

51. Andrews ZB, Liu ZW, Wallingford N, Erion DM, Borok E, Friedman JM, Tschöp MH, Shanabrough M, Cline G, Shulman GI, et al: UCP2 mediates ghrelin's action on NPY/AgRP neurons by lowering free radicals. Nature 454: 846-851, 2008.

52. Cheng G, Polito CC, Haines JK, Shafizadeh SF, Fiorini RN, Zhou X, Schmidt MG and Chavin KD: Decrease of intracellular ATP content downregulated UCP2 expression in mouse hepatocytes. Biochem Biophys Res Commun 308: 573-580, 2003.

53. Di Lisa F, Menabò R, Canton M, Barile M and Bernardi P: Opening of the mitochondrial permeability transition pore causes depletion of mitochondrial and cytosolic $\mathrm{NAD}^{+}$and is a causative event in the death of myocytes in postischemic reperfusion of the heart. J Biol Chem 276: 2571-2575, 2001.

54. Hunter FE Jr, Gebicki JM, Hoffsten PE, Weinstein J and Scott A: Swelling and lysis of rat liver mitochondria induced by ferrous ions. J Biol Chem 238: 828-835, 1963.

55. Baines CP, Song CX, Zheng YT, Wang GW, Zhang J, Wang OL, Guo Y, Bolli R, Cardwell EM and Ping P: Protein kinase Cepsilon interacts with and inhibits the permeability transition pore in cardiac mitochondria. Circ Res 92: 873-880, 2003.

56. Clarke SJ, McStay GP and Halestrap AP: Sanglifehrin A acts as a potent inhibitor of the mitochondrial permeability transition and reperfusion injury of the heart by binding to cyclophilin-D at a different site from cyclosporin A. J Biol Chem 277: 34793-34799, 2002 . 